Original Research Article

\title{
Evaluation of analgesic activity of Toxicodendron radicans in animal model using wistar albino rats
}

\author{
Marzana K. V., Nagapati Prabhakar Bhat*, Roopa P. Nayak, Megha Rani N.
}

Department of Pharmacology, Yenepoya college of Medicine, Mangaluru, Karnataka, India

Received: 22 April 2019 Accepted: 03 May 2019

\section{*Correspondence to: \\ Dr. Nagapati P.B, \\ Email: npbhat17@gmail.com}

Copyright: () the author(s), publisher and licensee Medip Academy. This is an openaccess article distributed under the terms of the Creative Commons Attribution NonCommercial License, which permits unrestricted noncommercial use, distribution, and reproduction in any medium, provided the original work is properly cited.

\begin{abstract}
Background: Pain forms an integral part of many clinical conditions management is of great importance in every field of medicine. The core of medicine is to preserve and restore patient's health and to minimize their suffering. Toxicodendron radicans (rhus toxicodendron) is a homoeopathic remedy with anti-inflammatory activity used for various arthritic pain. Rhus toxicodendron is commonly used in skin, mucus membrane affections, pain in joints, tendons, rheumatism in cold season, cellulitis and infection, fever. During the recent exponential rise in the use of alternative medicines and increasing integration into the health service little research has been done on alternative medicine in the context in which it is practiced.

Methods: Wistar albino rats were divided into four groups. group 1 received control (normal saline), group 2 received vehicle (alcohol with distilled water in ratio 1:4), and group 3 received standard (diclofenac-10 $\mathrm{mg} / \mathrm{kg}$ ), group 4 and 5 consist of 2 test groups-rhus toxicodendron 30x and 200c respectively. Analgesic activity was assessed using Hot water tail immersion method and Eddy's hot plate method. Preliminary pilot study was done with 4 doses rhus toxicodendron 6x, 12x, 30x, 200c respectively. Data was analysed by one-way ANOVA followed by Tukey Kramer multiple comparison test. $\mathrm{P}$ value $<0.05$ was considered as significant.
\end{abstract}

Results: In Eddy's hot plate method, rhus toxicodendron 30 showed increase in paw withdrawal time which was statistically very significant at the end of $1 \mathrm{hr}$ compared to the control group whereas statistically rhus toxicodendron 200 showed extremely significant analgesic property. In hot water tail immersion method rhus toxicodendron 30 showed increase in tail withdrawal time at the end of $1 \mathrm{hr}$ compared to the control group which was significant statistically.

Conclusions: This study shows that toxicodendron radicans homoeopathic formulations possess significant analgesic property.

Keywords: Analgesic, Eddy's hot plate, Hot water tail immersion, Rhus toxicodendron

\section{INTRODUCTION}

Since the beginning of life on earth, human race has been afflicted by the disease in one form or the other. The collective aim of medical profession throughout the ages has been to fight disease with view of relieving human race. Pain forms an integral part of many clinical conditions, management of pain is of great importance in every field of medicine. Ineffective pain management can affect clinical and psychological outcomes and also patient's overall quality of life. The core of medicine is to preserve and restore patient's health and to minimize their suffering. Pain is universally understood as a pointer of 
disease and it brings the patient to the physician recognition. ${ }^{1}$

During the recent exponential rise in the use of alternative medicines and increasing integration into the health service, little research has been done on alternative medicine in the context in which it is practiced, or over time to look at changing belief system. ${ }^{2}$

Homoeopathy is a national medical system, the market is growing at $25 \%$ a year, $15 \%$ of Indian population depend solely on this form of therapy for their health care needs. Toxicodendron radicans (Rhus toxicodendron) is a homoeopathic remedy with anti-inflammatory activity used for various arthritic pain. Rhus toxicodendron grows as a shrub or a woody vine, spreading all over the countryside as a weed in the Eastern USA and Canada. The remedy was introduced into homeopathy by Hahnemann. Rhus toxicodendron is commonly used in skin, mucus membrane affections, pain in joints, tendons, Rheumatism in cold season, cellulitis and infection, fever. ${ }^{3}$

\section{METHODS}

This study was conducted in the Ethno pharmacology lab, Department of Pharmacology, Yenepoya Medical College Mangaluru, Karnataka, India after obtaining the approval from the Institutional Animal Ethics Committee (IAEC).

\section{Experimental animals}

Healthy adult Wistar albino rats of 6 months to 1 year of age weighing 200-300g were used for the study. They were housed in clean polypropylene cages, six rats in each cage, under standard housing conditions, maintained at room temperature of $24+1$ oC, $12 / 12$-hour light/dark cycle in the departmental animal house (347/PO/RES/RCL/01/CPCSEA). They had free access to standard pellet diet (obtained from amruth feeds, sangali) and water. They were marked with haematoxylin stain for the purpose of identification.

The animals were acclimatized to the laboratory conditions for one week prior to the experiment. They were handled as per CPCSEA (Committee for the Purpose of Control and Supervision of Experiments on Animals) guidelines. ${ }^{4}$ All the experiments were carried out between 9-5PM.

\section{Rhus toxicodendron homoeopathic formulation procurement}

Rhus toxicodendron homoeopathic formulations where be procured from Mangaluru homoeopathic pharmacy manufactured by Dr. Willmar Schwabe India Pvt. Ltd. A subsidiary of Schwabe International GmbH, Germany.

\section{Chemicals}

Distilled water, Normal saline, Diclofenac sodium.

\section{Standard drug \\ Diclofenac Sodium. ${ }^{5}$}

\section{Acute toxicity study TRAE}

The acute toxicity of alcoholic extract of Toxicodendron radicans (TRAE) was done according to organisation for economic Cooperation and development (OECD) guidelines 425 limit test. 6 at the dose of $2000 \mathrm{mg} / \mathrm{kg}$. A dose of $2000 \mathrm{mg} / \mathrm{kg}$ of TRAE was administered orally to 5 female wistar albino rats which were fasted overnight. Animals were observed individually once during the first 30 minutes after dosing, hourly in the first $4 \mathrm{hrs}$, at $24 \mathrm{hrs}$ and daily thereafter, for a total of 14 days, it was observed for changes in skin and fur, eyes and mucous membranes. Also any changes in respiratory (depression, stimulation, failure), circulatory (blanching, cyanosis, vasodilation), autonomic and central nervous system, and somatomotor activity and behavioural pattern were observed. Attention was also directed to writhing, convulsions, salivation, diarrhoea, lethargy, sleep and coma.

\section{Preparation of test drug TRHF}

The dose of Toxicodendron radicans homeopathic formulation (Rhus toxicodendron) was fixed to 30 and 200 after performing pilot study with $3 \mathrm{x}, 12 \mathrm{x}, 30$ and 200 .

\section{Dosing of animals}

The required amount of test potencies (30x and 200c) of toxicodendron radicans and vehicle $(91.5 \% \mathrm{v} / \mathrm{v}$ alcohol used as vehicle for preparation of different potencies of test drug) were diluted with distilled water in the ratio of 1:4 and kept as stock solutions. The animals were fed with 2 $\mathrm{ml}$ stock solution of different potencies (30 and 200) of toxicodendron radicans i.e., $0.5 \mathrm{ml}$ (drug)/rat/ day for 10 days. Vehicle and saline-treated rats were tested simultaneously along with drug-treated animals. ${ }^{7}$

\section{Experimental procedure}

The study was carried out for analgesic activity by using following animals screening methods..$^{8-11}$

\section{Eddy's hot plate}

Wistar albino rats albino rats of either sexes weighing between 150-300g were used. The drug was given orally for 10 days. The animals were placed on Eddy's hot plate maintained $55+1^{\circ} \mathrm{C}$ at for maximum time of $30 \mathrm{sec}$. latency to exhibit nociceptive response such as licking their fore and hind paws or jumping determined. A cut off time of 60 $\mathrm{s}$ to avoid tissue damage was maintained.

\section{Hot water tail immersion test in rats}

Young Wistar albino rats of either sexes weighing between $150-300 \mathrm{~g}$ were used. The drug was given orally for 10 days 
to all the five groups. The experiment was done $1 \mathrm{hr}$ following drug administration on the 10th day. The lower $5 \mathrm{~cm}$ of the rat tail was marked and immersed in a beaker of freshly filled water maintained at around $55+1^{\circ} \mathrm{C}$ and the reaction time for tail curling and flicking moment was recorded using stopwatch (Figure1). After each test the tail was carefully dried.

\section{Calculating percentage analgesic score}

The formula for calculating percentage analgesic score

$$
\% \text { Analgesic score }=\frac{\mathrm{Ta}-\mathrm{Tb}}{\mathrm{Ta}} \times 100
$$

Where,

Ta-Reaction time in seconds after drug administration Tb-Reaction time in seconds before drug administration

\section{Statistical analysis}

Data was compiled and analyzed using statistical package, Graph Pad Instat software. Results are represented as Mean \pm SEM (standard error of mean). Statistical significance between means was analyzed using one-way ANOVA followed by the Tukey Kramer multiple comparison test. Values of $\mathrm{P}>0.05$ were considered as statistically significant

\section{RESULTS}

\section{Acute toxicity study of TRAE}

After the administration of single dose of $2000 \mathrm{mg} / \mathrm{kg}$ of TRAE, no mortality was observed in rats. There was no change in skin color, or respiratory depression, no excessive salivation, no writhing movement seen.

Table 1: Effect of TRHF on paw withdrawal time (in sec) by Eddy's hot plate method in rats.

\begin{tabular}{|ll|}
\hline Groups & Paw withdrawal time (time in seconds) \\
\hline Control & $3.33 \pm 0.21$ \\
\hline Vehicle & $4.8 \pm 0.28$ \\
\hline Standard & $11.51 \pm 0.64 * * *$ \\
\hline RT 30 & $6.41 \pm 0.53 * *$ \\
\hline RT 200 & $9.27 \pm 96 * *$ \\
\hline
\end{tabular}

$* \mathrm{p}<0.05$ - Significant, $* * \mathrm{p}<0.01$ - very significant, $* * * \mathrm{p}<0.001-$ extremely significant. RT- Rhus toxicodendron

\section{Eddy's hot plate}

In Eddy's hot plate method for screening of central analgesic activity standard, RT 30, RT200 showed significant increase in the paw withdrawal time (Figure 1). $\mathrm{P}$ value of RT 30 showed $<0.01$ compared to the control which suggesting of significance. P value of RT 200 showed $<0.00$ which suggests it is extremely significant in comparison with control. P value of RT200 showed $<0.001$ compared to the vehicle which suggests it is extremely significant at the end of $1 \mathrm{hr}$ (Table 1).

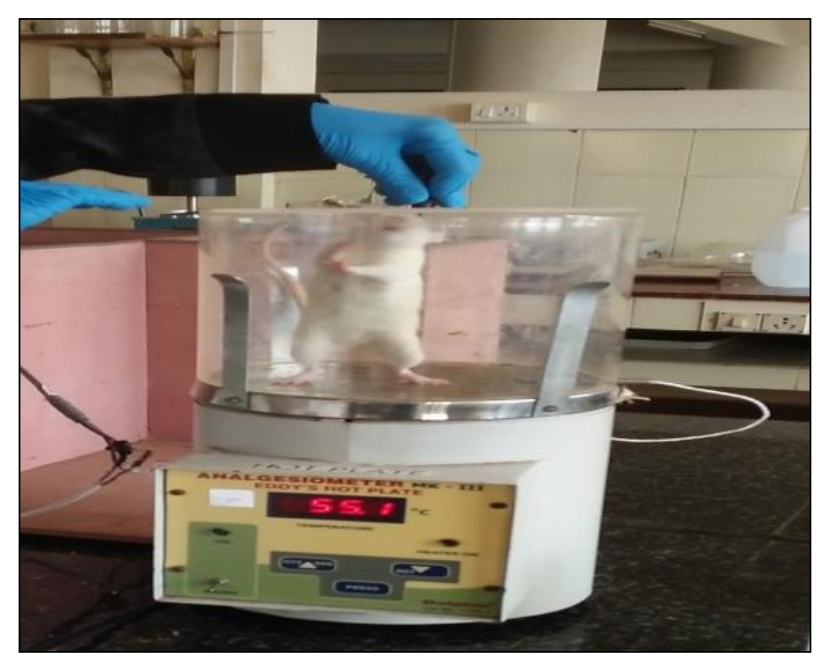

Figure 1: Eddy's hot plate.

\section{Hot water tail immersion test in Wistar albino rats}

In the hot water tail immersion test for screening of central analgesic activity, RT 30showed significant increase in the tail withdrawal time (Figure 2) whose $\mathrm{P}$ value is $<0.001$ (Table 2) which suggest that it is extremely significant, whereas RT200 was not significant in comparison with vehicle at the end of $1 \mathrm{hr}$ compared to the control.

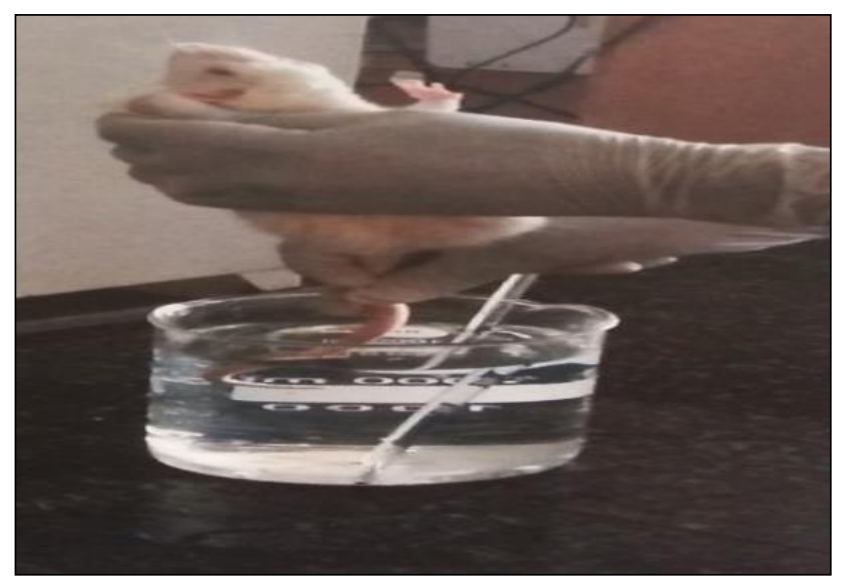

Figure 2: Hot water tail immersion.

Table 2: Effect of RT30 and RT200 on tail flick in seconds in hot water tail immersion tests.

\begin{tabular}{|lc|}
\hline Groups & Tail curl / flick time in seconds \\
\hline Control & $3.16 \pm 0.30$ \\
\hline Vehicle & $3.51 \pm 0.09$ \\
\hline Standard & $3.80 \pm 0.16$ \\
\hline RT 30 & $5.11 \pm 0.44^{* * *}$ \\
\hline RT 200 & $4.09 \pm 0.33$ \\
\hline
\end{tabular}

$* \mathrm{p}<0.05$ - Significant, $* * \mathrm{p}<0.01$ - very significant, $* * * \mathrm{p}<0.001$ extremely significant. RT- Rhus toxicodendron 


\section{Percentage analgesic score of Toxicodendron radicans (Rhus toxicodendron) homoeopathic formulation}

Percentage analgesic score was calculated for the standard drug (diclofenac- $10 \mathrm{mg} / \mathrm{kg}$ ), RT 30 and 200 using standard formula by substituting mean values of reaction time in seconds (Table 3).

Results were represented graphically in comparison with standard drug (Figure 3). Values of standard and test groups were represented on $\mathrm{x}$ axis and percentage analgesic score on y axis. On assessing graphically standard drug showed maximum percentage analgesic score $(71.07 \%)$, RT 200 showed better analgesic score (64.07\%) in comparison with RT30 (48.04\%).

Table 3: Mean values of reaction time in seconds Standard drug, RT30 and RT 200.

\begin{tabular}{|llll|}
\hline & $\begin{array}{l}\text { Standard drug } \\
\text { (Mean) }\end{array}$ & $\begin{array}{l}\text { RT 30 } \\
\text { (Mean) }\end{array}$ & $\begin{array}{l}\text { RT 200 } \\
\text { (Mean) }\end{array}$ \\
\hline $\mathrm{Ta}$ & 11.51 & 6.41 & 9.27 \\
\hline $\mathrm{Tb}$ & 3.33 & 3.33 & 3.33 \\
\hline
\end{tabular}

- Percentage analgesic score for standard drug is $71.07 \%$.

- Percentage analgesic score for RT30 is $48.04 \%$

- Percentage analgesic score for RT 200 is $64.07 \%$

\begin{tabular}{|c|c|c|c|}
\hline & Standard & RT 30 & RT 200 \\
\hline $80.00 \%$ & & & \\
\hline $70.00 \%$ & & & \\
\hline $60.00 \%$ & & & \\
\hline $50.00 \%$ & & & \\
\hline $40.00 \%$ & & & \\
\hline $30.00 \%$ & & & \\
\hline $20.00 \%$ & & & \\
\hline $10.00 \%$ & & & \\
\hline $0.00 \%$ & Standard & RT 30 & RT 200 \\
\hline
\end{tabular}

Figure 3: Percentage analgesic score of toxicodendron radicans (rhus toxicodendron) homoeopathic formulation.

\section{DISCUSSION}

The present study was carried out to evaluate the analgesic activity of toxicodendron radicans homoeopathic formulation in wistar albino rats. Toxicodendron radicans (Rhus toxicodendron) belongs to anacardiaceae family, in the homoeopathic system of medicine this remedy frequently indicated on the skin, rheumatic pains, mucous membrane affections, and a typhoid type of fever. Rhus tox affects fibrous tissue markedly-joints, tendons, sheaths-aponeurosis etc. producing pains and stiffness. Post-operative complications, ailments from strains, Septic conditions, cellulitis and infections, carbuncles in early stages, rheumatism in the cold season, septicemia. ${ }^{12}$

In this study evaluation of analgesic activity of toxicodendron radicans (rhus toxicodendron) at the dose of 30 and 200 was carried out by Eddy's hot plate method and Hot water tail immersion test using wistar albino rats as the experimental animal. Eddy's hot plate method and Hot water tail immersion test are valid screening models for centrally acting analgesic drugs.

Analgesics are drugs that act on peripheral or central nervous system to selectively relieve pain without significantly altering consciousness. Centrally acting analgesics act by raising the threshold for pain and also altering the physiological response to pain. ${ }^{13}$ On the other hand, peripherally acting analgesics act by inhibiting the generation of impulses at chemoreceptor site of pain. ${ }^{14}$

The animal models employed for screening of analgesic activity in this study are pain state models using thermal stimuli which include Hot water tail immersion and Eddy's hot plate methods. In present study RT 200 showed extremely significant analgesic activity, RT 30 showed very significant analgesic activity in Eddy's hot plate method.

Whereas in Hot water tail immersion test RT 30 has showed significant analgesic activity. Both these methods are useful in illustrating centrally mediated antinociceptive responses. Analgesic drugs that are centrally acting elevate pain threshold of animals towards heat and pressure. It is well established that thermal nociceptive tests are sensitive to $\mu$ opioid agonists and non-thermal tests to $\mathrm{K}$ opioid agonists. $^{15}$

The above models typically utilize changes in the threshold stimulus intensity (e.g. temperature/mechanical) to initiate a response or latency to escape (i.e., evoked behaviours). Some of these behaviours may employ a response phenotype organized at the spinal level, like the tail flick response seen in Hot water tail immersion test. Technically, this is a poly synaptic reflex movement of the tail, which is evoked by an acute high intensity thermal stimulus applied to the tail of the animal. Eddy's hot plate model may involve higher brain functions. The response seen in Eddy's hot plate such as withdrawal of hind paw requires complex motor coordination, and it is regarded as supraspinally organized response. ${ }^{16}$

The objective of the present study was to examine the analgesic of Rhus toxicodendron homoeopathic formulation $\left(30^{\circ} \mathrm{C}\right.$ and 200$)$ in albino rats. Positive results are obtained in animal models, the analgesic activities of different potencies $\left(30^{\circ} \mathrm{C}\right.$ and 200$)$ of Rhus toxicodendron in rats were evaluated by using hot plate method, tail immersion method. The data obtained for its analgesic effects revealed that both 30x and 200c had increased the 
latency times for both thermal noxious stimulus and had also increased the quantum of threshold pressure to mechanical induced pain when measured on 10th day of study $1 \mathrm{hr}$ after the administration of the drug. The level of significance varied not only between the potencies of the drug but also between different sets of experiments when compared than that of normal.

\section{ACKNOWLEDGEMENTS}

Authors would like to thank Department of pharmacology, Yenepoya Medical College, Mangaluru, Karnataka, India for their support during study.

Funding: No funding sources Conflict of interest: None declared

Ethical approval: The study was approved by the Institutional Animal Ethics Committee

\section{REFERENCES}

1. Kumar KH, Elavarasi P. Definition of pain and classification of pain disorders. Journal of Advanced Clinical and Research Insights. 2016;3(3):87-90.

2. Ernst E. Prevalence of use of complementary/alternative medicine: a systematic review. Bulletin of the world Health Organization. 2000;78(2):252-7.

3. Boericke W. Pocket manual of Homoeopathic Materia Medica and Repertory. New Delhi: B. Jain Publishers: 2007: 489-491.

4. Parmar NS, Shiv Prakash. Screening methods in pharmacology. Kolkata: Narosa publishing house pvt ltd; 2006:225-235.

5. Rahul DY, Jain SK, Alok S, Sharma S. Analgesic activity of ethanolic extract of Pongamia pinnata Linn. Leaves. Scholars Research Library. 2011;3(5):180.

6. Guidelines OECD 425. Acute oral toxicity up and down procedure in OECD guidelines for the testing of chemicals, Organization for Economic Cooperation and Development. 2001;2:12

7. Sundaram EN, Singh PK, Reddy PK, Kumar S, Nair J, Raven K, Khurana A, et al. Preliminary study to evaluate analgesic and behavioural effects of Lycopodium clavatum in experimental animals. Indian J Res Homoeo. 2013;7(40):168-74.

8. HG Vogel. Analgesic, anti-inflammatory and antipyretic activity. In: drug discovery and evaluation: Pharmacological assays .3rd ed. New York, Springer Verlag; 2008:1013-1014.

9. S.K Gupta. Drug screening methods.3rd ed. New Delhi: Jaypee brother's medical publishers; 2015:476494.

10. Bikash Medhi, AjayPrakash. Practical manual of experimental and clinical pharmacology. New Delhi: Jaypee brothers medical publishers; 2010:256-259.

11. N S Parmar, Shiv prakash. Screening methods in pharmacology. Kolkata: Narosa publishing house pvt ltd; 2006:225-235.

12. D.D Banerjee. Augmented textbook of homoeopathic pharmacy. New Delhi, B. Jain Publishers; 2009:652.

13. Alam B, Akter F, Parvin N, Pia RS, Akter S, Chowdhury J, et al. Antioxidant, analgesic and antiinflammatory activities of the methanolic extract of Piper betle leaves. Avicenna J Phytomee. 2013;3(2):112.

14. Fan SH, Ali NA, Basri DF. Evaluation of analgesic activity of the methanol extract from the galls of quercus infectoria (Olivier) in Rats. Evidence based complementary and alternative medicine. 2014;1-6.

15. Adeyemi OO, Adeneye AA, Alabi TE. Analgesic activity of the aqueous seed extract of Hunteria Umbellata (K.Schum) hallier F. in rodents. Indian J experiment bio. 2011;49(9):698-703.

16. Yaksh TL, Woller SA, Ramachandran R, Sorkin LS. The search for novel analgesics: targets and mechanisms. F1000prime reports. 2015;7:56.

Cite this article as: Marzana KV, Bhat NP, Nayak RP, Megha Rani N. Evaluation of analgesic activity of Toxicodendron radicans in animal model using wistar albino rats. Int $\mathrm{J}$ Basic Clin Pharmacol 2019;8:1582-6. 